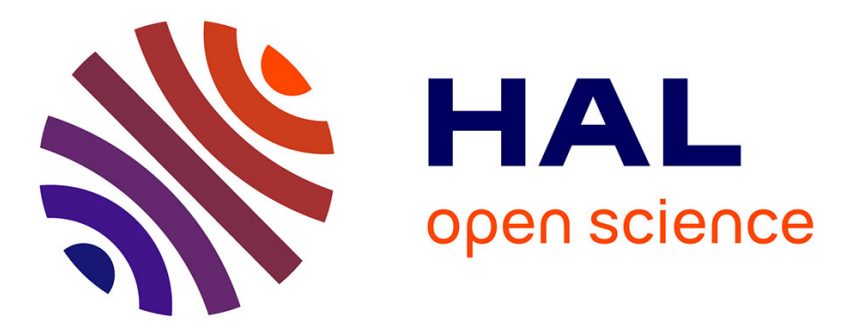

\title{
Right Harmonic Spectrum for the back-electromotive force of a n-phase synchronous motor
}

\author{
Eric Semail, Xavier Kestelyn, Alain Bouscayrol
}

\section{To cite this version:}

Eric Semail, Xavier Kestelyn, Alain Bouscayrol. Right Harmonic Spectrum for the back-electromotive force of a n-phase synchronous motor. IEEE Industrial Application Society Annual Meeting, Oct 2004, Seattle, United States. pp.1-8, 10.1109/IAS.2004.1348390 . hal-01109558

\section{HAL Id: hal-01109558 \\ https://hal.science/hal-01109558}

Submitted on 26 Jan 2015

HAL is a multi-disciplinary open access archive for the deposit and dissemination of scientific research documents, whether they are published or not. The documents may come from teaching and research institutions in France or abroad, or from public or private research centers.
L'archive ouverte pluridisciplinaire HAL, est destinée au dépôt et à la diffusion de documents scientifiques de niveau recherche, publiés ou non, émanant des établissements d'enseignement et de recherche français ou étrangers, des laboratoires publics ou privés. 


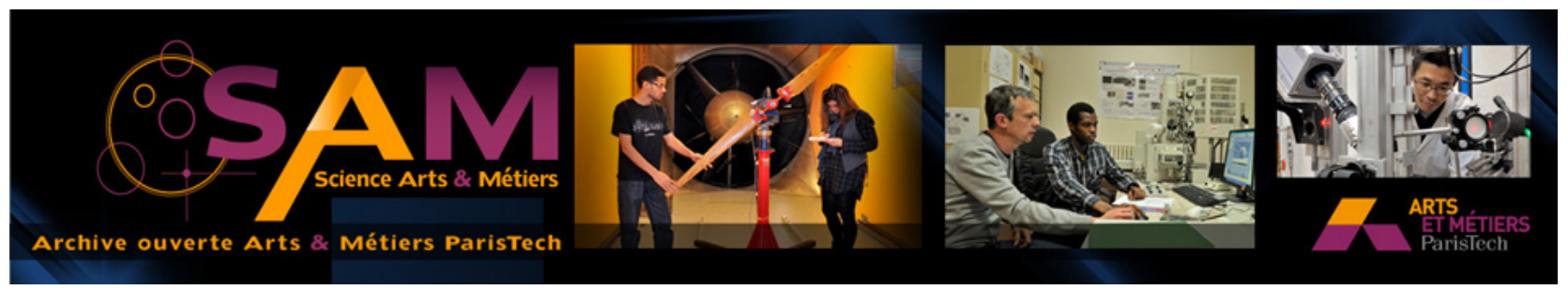

Science Arts \& Métiers (SAM)

is an open access repository that collects the work of Arts et Métiers ParisTech researchers and makes it freely available over the web where possible.

This is an author-deposited version published in: http://sam.ensam.eu

Handle ID: .http://hdl.handle.net/10985/9274

\section{To cite this version :}

Eric SEMAIL, Xavier KESTELYN, Alain BOUSCAYROL - Right Harmonic Spectrum for the backelectromotive force of a n-phase synchronous motor - In: IEEE Industrial Application Society Annual Meeting, Etats-Unis, 2004-10 - IAS congress - 2004 


\title{
Right Harmonic Spectrum for the Back-Electromotive Force of a $n$-phase Synchronous Motor
}

\author{
Eric Semail, Member IEEE, Xavier Kestelyn, Alain Bouscayrol, Member IEEE \\ L2EP, Laboratoire d'Electrotechnique et d' Electronique de Puissance de Lille \\ ENSAM, USTL \\ LILLE, FRANCE \\ eric.semail@lille.ensam.fr
}

\begin{abstract}
This paper deals with a vector control of $n$-phase permanent magnet synchronous machine. To use control algorithms already developed for sine-wave 3-phase machines, the spectrum of back electromotive force (EMF) must contain only odd $2 k+1$ harmonics which verify the following inequality, $1 \leq 2 k+1<n$. In an experimental vector control of a 5-phase drive, two usual algorithms of sine-wave 3-phase machine are thus used to supply a machine with trapezoidal waveform back EMF. In this case, the first and third harmonics are used to produce torque: the other harmonics, and particularly the $7^{\text {th }}$ one, induce effects as torque ripples and parasitic currents.
\end{abstract}

Keywords- multi-phase; synchronous motor; multi-machine.

\section{INTRODUCTION}

Multi-phase machines have several advantages over conventional 3-phase ones [1]-[2] such as higher reliability and reduction of the torque pulsation magnitude. Nevertheless, their vector controls are not known as well as those of 3-phase BLDC machines [3]. For these last ones, two kinds of controls are usually distinguished on the basis of back EMF waveforms. If the back EMFs have a sinusoidal waveform then current controls in synchronous frame achieve high efficient brushless DC machines. If the back EMFs have trapezoidal waveforms, the control in stationary frame is simpler but also less efficient

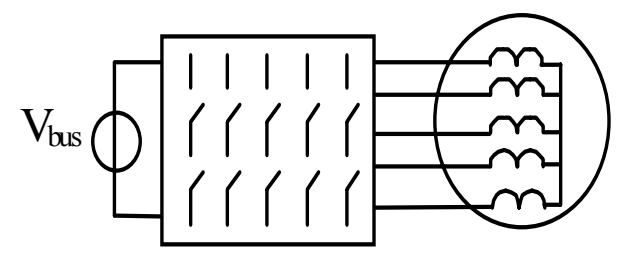

Figure 1. Symbolic representation of the 5-leg PWM-VSI and wye-coupled 5-phase machine.

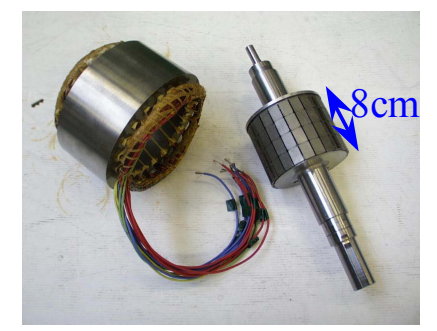

Figure 2. Experimental 5-phase motor.
[3]. For $n$-phase machines, particular controls have already been proposed [4]-[6] but there is no synthetic approach. This simple classification is no more obvious for $n$-phase machines. In fact, a more accurate harmonic analysis of back EMF is necessary to distinguish between two kinds of machines which make possible two kinds of performances. We consider only the case of machines whose number of phases is a odd number. If the harmonic spectrum of a $n$-phase machine contains only odd harmonics strictly inferior to $n$, then it is possible to achieve equivalent controls as those of sine-wave 3-phase machines. In this paper, the particular case of a 5-phase experimental (Fig1. Fig.2 Fig.3) drive is used to highlight the influence of harmonics on the vector control.

\section{MULTI-MACHINE CHARACTERIZATION OF A $n$-PHASE MACHINE}

Under assumptions of no saturation, no reluctance effect and regular spatial distribution of windings, the vectorial approach developed in [7]-[9] leads to define the equivalence of a $n$ phase wye-connected machine to a set of $(n-1) / 2$ fictitious independent 2-phase machines.

\section{A. Assumptions, notations, nomenclature}

1) Nomenclature

All quantities relating to the phase $\mathrm{n}^{\circ} k$ are written $x_{k}$.

- $j_{s k}$ : current in the phase $\mathrm{n}^{\circ} k$;

- $u_{s k}$ : voltage across the phase $\mathrm{n}^{\circ} k$;

- $\phi_{s k}$ : flux through the phase $\mathrm{n}^{\circ} k$ exclusively produced by the stator currents;

- $\phi_{s r k}$ : flux through the phase $n^{\circ} k$ exclusively due to the rotor magnets;

- $e_{k}$ : electromotive force (EMF) induced in the phase $\mathrm{n}^{\circ} k$ only due to the rotor magnets;

- $\theta$. mechanical angle.

2) Assumptions

Usual assumptions are used to model the machine:

- all phases are identical and regularly shifted by an angle (Fig.4):

$$
\alpha=\frac{2 \pi}{n}
$$


- effects of saturation and damper windings are neglected.

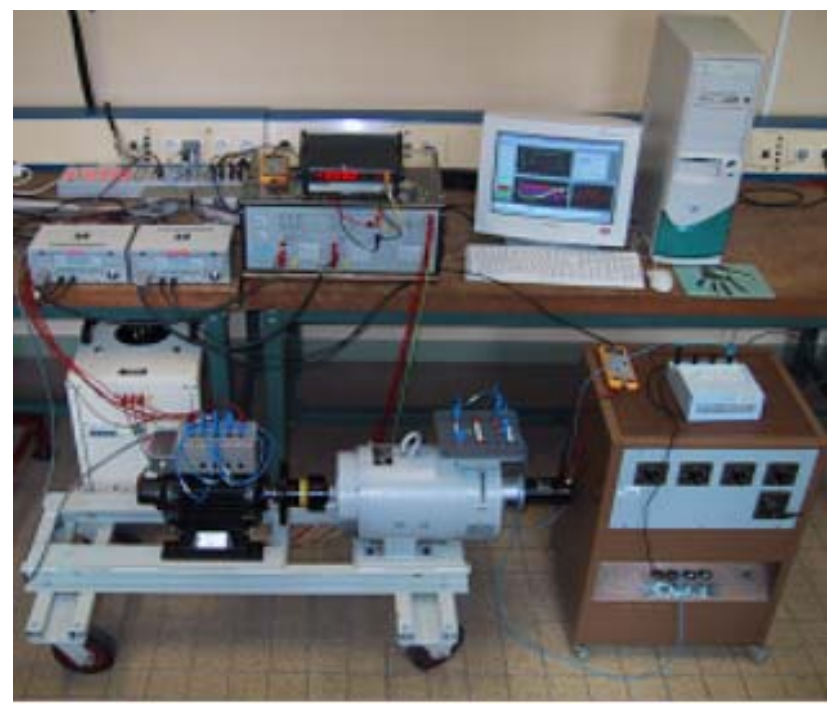

Figure 3. Experimental drive.

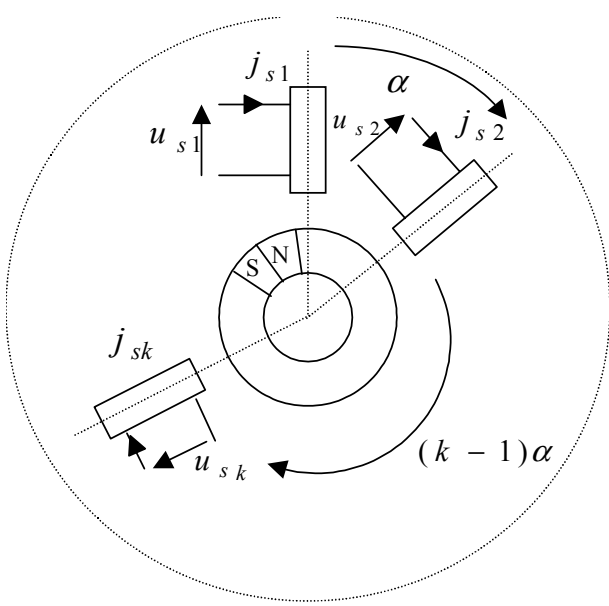

Figure 4. Presentation of $n$-phase PM machine.

\section{B. Usual modeling in a natural base}

In the usual matricial approach of $n$-phase machines, a vector $n$-space is implicitly considered since vectors with $n$ components are defined. This space is provided with an orthonormal base $B_{\sigma}=\left\{\overrightarrow{x_{1}^{\sigma}}, \overrightarrow{x_{2}^{\sigma}}, \ldots, \overrightarrow{x_{n}^{\sigma}}\right\}$ that can be called "natural" since the coordinates of a vector in this base are the measurable values relative to each phase.

In this paper, we consider that this space is an Euclidean vectorial space with the usual canonical dot product.

In this natural base, different vectors are defined:

$$
\begin{aligned}
& \overrightarrow{u_{s}}=u_{s 1} \overrightarrow{x_{1}^{\sigma}}+u_{s 2} \overrightarrow{x_{2}^{\sigma}}+\ldots+u_{s n} \overrightarrow{x_{n}^{\sigma}} \\
& \overrightarrow{j_{s}}=j_{s 1} \overrightarrow{x_{1}^{\sigma}}+j_{\mathrm{s} 2} \overrightarrow{x_{2}^{\sigma}}+\ldots+j_{s n} \overrightarrow{x_{n}^{\sigma}}
\end{aligned}
$$

$$
\begin{aligned}
& \vec{\phi}_{s}=\phi_{s 1} \overrightarrow{x_{1}^{\sigma}}+\phi_{\mathrm{s} 2} \overrightarrow{x_{2}^{\sigma}}+\ldots+\phi_{s n} \overrightarrow{x_{n}^{\sigma}} \\
& \vec{e}=e_{1} \overrightarrow{x_{1}^{\sigma}}+e_{2} \overrightarrow{x_{2}^{\sigma}}+\ldots+e_{n} \overrightarrow{x_{n}^{\sigma}}
\end{aligned}
$$

Taking into account $R_{s}$, the stator resistance per phase, the vectorial voltage equation is:

$$
\overrightarrow{u_{s}}=R_{s} \overrightarrow{j_{s}}+\left[\frac{d \vec{\phi}_{s}}{d t}\right]_{/ B_{\sigma}}+\vec{e}
$$

The $\mathrm{B}_{\sigma}$ index reminds that differentiation is operated according to the $\mathrm{B}_{\sigma}$ natural base.

This equation can be projected onto each vector of the natural base to find again the more usual equation:

$$
u_{s k}=\overrightarrow{u_{s}} \cdot \overrightarrow{x_{k}^{\sigma}}=R_{s} j_{s k}+\frac{d \phi_{s k}}{d t}+e_{k}
$$

The assumptions previously defined allow to write a linear relation between the stator current vector and the stator flux vector:

$$
\overrightarrow{\phi_{s}}=\Lambda_{s}\left(\overrightarrow{j_{s}}\right)
$$

usually written with the circular matrix notation:

$$
\left[\mathrm{L}_{s}^{\sigma}\right]=\operatorname{Mat}\left[\Lambda_{s}, B_{\sigma}\right]=\left(\begin{array}{cccc}
\mathrm{M}_{\mathrm{s}_{1} \mathrm{~s}_{1}} & \mathrm{M}_{\mathrm{s}_{1} \mathrm{~s}_{2}} & \ldots & \mathrm{M}_{\mathrm{s}_{1} \mathrm{~s}_{n}} \\
\mathrm{M}_{\mathrm{s}_{1} \mathrm{~s}_{\mathrm{n}}} & \mathrm{M}_{\mathrm{ss}_{1} 1} & \ldots & \mathrm{M}_{\mathrm{s}_{1} \mathrm{~s}_{n-1}} \\
\ldots & \ldots & \ldots & \ldots \\
\mathrm{M}_{\mathrm{s}_{1} \mathrm{~s}_{2}} & \mathrm{M}_{\mathrm{s}_{1} \mathrm{~s}_{3}} & \ldots & \mathrm{M}_{\mathrm{s}_{1} \mathrm{~s}_{1}}
\end{array}\right)
$$

The modeling of the machine in the natural base is not simple because of the complexity of the matrix $\left[\mathrm{L}_{s}^{\sigma}\right]$. It would be interesting to find a simpler form for matrix of $\Lambda_{s}$.

\section{Vectorial decomposition in eigenspaces of $\Lambda_{S}$}

The equation (8) is true whatever is the chosen base associated with the stator coils. The symmetry and circularity of the inductance matrix $\left[\mathrm{L}_{s}^{\sigma}\right]$ allows to state that:

- $\quad \Lambda_{s}$ belongs $F$ eigenvalues $L_{g}$ with $F=(n+1) / 2$ and

$$
L_{g}=\sum_{e=1}^{e=n} M_{s_{I} s_{e}} \cos \left(\frac{2 \pi}{n} g(e-1)\right)
$$

- the $F$ associated eigenspaces $G_{g}$ are orthogonal each other;

- the $G_{0}$ eigenspace, associated with the eigenvalue $L_{0}$, is a vectorial line;

- the others $(n-1) / 2$ eigenspaces $G_{2 g}(1 \leq g \leq(n-1) / 2)$, associated with the others $(n-1) / 2$ eigenvalues $L_{g}$ are vectorial planes. A base of $G_{2 g}$ plane is:

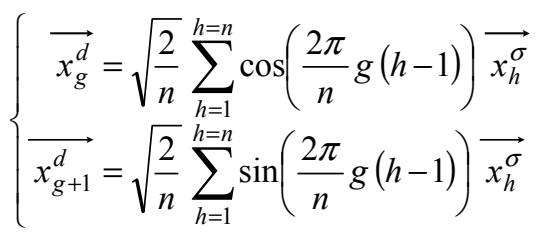


The orthogonality of the $G_{2 g}$ planes allows to decompose every vector $\vec{y}$ into a sum of vectors $\overrightarrow{y_{g}}$ obtained by orthogonal projection of $\vec{y}$ onto $G_{2 g}$ :

$$
\vec{y}=\sum_{g=0}^{g=F-1} \overrightarrow{y_{g}}
$$

This kind of decomposition has already been achieved in particular cases [10] for induction machines.

Finally, as $L_{g}$ are eigenvalues of $\Lambda_{s}$, a simpler expression between flux and currents can be expressed:

$$
\overrightarrow{\phi_{s}}=\sum_{g=0}^{g=F-1} \overrightarrow{\phi_{g}}=\sum_{g=0}^{g=F-1} L_{g} \overrightarrow{j_{g}}
$$

\section{Multi-machine concept}

It is now possible to show that the torque of a multi-phase machine can be decomposed into a sum of torques of machines which are magnetically decoupled.

First, the electric power in the stator is expressed:

$$
p_{s}=\sum_{k=1}^{k=n} u_{s k} j_{s k}=\overrightarrow{u_{s}} \cdot \overrightarrow{j_{s}}
$$

From (6) we obtain:

$$
p_{s}=\overrightarrow{u_{s}} \cdot \overrightarrow{j_{s}}=R_{s} \overrightarrow{j_{s}} \cdot \overrightarrow{j_{s}}+\left[\frac{d \overrightarrow{\phi_{s}}}{d t}\right]_{B_{\sigma}} \cdot \overrightarrow{j_{s}}+\overrightarrow{e_{s}} \cdot \overrightarrow{j_{s}}
$$

With the previous assumptions, the eigenvalues and eigenvectors are constant, the electromotive force does not depend on currents. We have then:

$$
\left[\frac{d \overrightarrow{\phi_{s}}}{d t}\right]_{B_{\sigma}}=\sum_{g=1}^{g=F} L_{g} \frac{d \overrightarrow{j_{g}}}{d t}
$$

and

$$
\overrightarrow{e_{s}}=\left(\frac{d \theta}{d t}\right) \frac{d \overrightarrow{\phi_{s r}}}{d \theta}
$$

Therefore, as the eigenspaces are orthogonal each other, (14) becomes:

$$
\begin{gathered}
p_{s}=\overrightarrow{u_{s}} \cdot \overrightarrow{j_{s}}=\sum_{g=0}^{g=F-1}\left(R_{s}\left(\overrightarrow{j_{g}}\right)^{2}+L_{g} \frac{d \overrightarrow{j_{g}}}{d t} \cdot \overrightarrow{j_{g}}+\left(\frac{d \theta}{d t}\right) \frac{d \overrightarrow{\phi_{s r g}}}{d \theta} \cdot \overrightarrow{j_{g}}\right)= \\
\sum_{g=0}^{g=F-1}\left(R_{s}\left(\overrightarrow{j_{g}}\right)^{2}+\frac{d \frac{1}{2} L_{g}\left(\overrightarrow{j_{g}}\right)^{2}}{d t}+\left(\frac{d \theta}{d t}\right) \frac{d \overrightarrow{\phi_{s r g}}}{d \theta} \cdot \overrightarrow{j_{g}}\right)
\end{gathered}
$$

The first term can be considered as stator Joule losses, the second term as derivative of stator magnetic energy and the third as the product of angular speed $d \theta / d t$ by torque:

$$
T_{2 g}=\frac{d \overrightarrow{\phi_{s r g}}}{d \theta} \cdot \overrightarrow{j_{g}}
$$

The wye-coupling implies that $j_{0}=\sum_{k=1}^{k=n} j_{s k}=0$.

The total torque $T_{e m}$ is then:

$$
T_{e m}=\sum_{g=1}^{g=F-1} T_{2 g}
$$

So we can consider $(F-1)$ fictitious machines, each one of them being associated with one eigenspace. These machines are magnetically independent and have two phases since the dimension of their associated eigenspaces is two. These 2phase machines are electrically and mechanically coupled.

A very well-known case is the wye-coupled 3-phase machine that is considered to be equivalent to only one 2-phase machine in d-q theory. The control of the torque of such 3phase machine is then equivalent to this one of the 2-phase fictitious machine. In this case, it is obvious that the proposed approach is not interesting.

In the case of a wye-coupled 5-phase machine, there are two fictitious 2-phase machines named MM (Main Machine, $g=1$ ) and SM (Secondary Machine, $g=2$ ) which produces respectively the torque $T_{2}$ and $T_{4}$. Consequently, for the control of the 5-phase machine, a choice must be done to define the two references $T_{2 \text {-ref }}$ and $T_{4 \text {-ref }}$ from a unique torque reference $T_{\text {em-ref. }}$ Of course, the choice depends on the characteristics of the two fictitious machines but also of the supply of the 5phase machine. The designer must simultaneously take into account these two aspects [11].

This kind of problem is the same as found into multimachine control. So, we propose to use a formalism developed for these systems [12]-[13]. The considered approach (Fig.5) highlights the electrical and mechanical couplings (the intersecting rectangles and triangles) between the two fictitious machines (the circles).

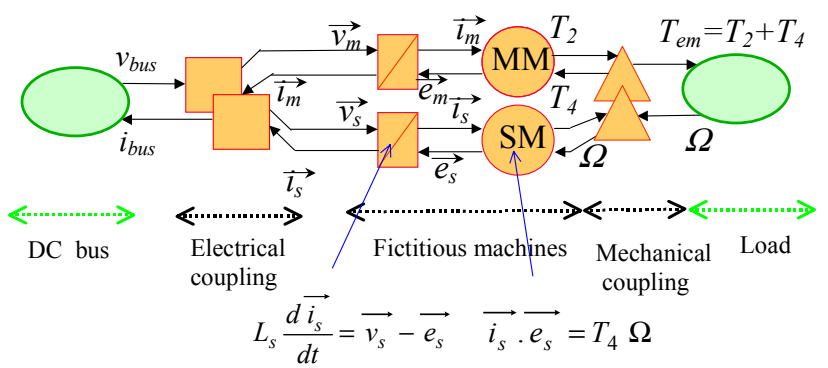

Figure 5. Multi-machine Representation of a 5-phase machine.

To control a multi-machine system, it is necessary to characterize each machine. In the following section, an 
harmonic characterization of the fictitious machines is presented.

\section{HARMONIC CHARACTERIZATION OF FICTITIOUS MACHINES}

We prove that for a $n$-phase machine, a machine $n^{\circ} g$ is associated with the family of $n h \pm g$ odd harmonics $(1 \leq g \leq(n-1) / 2)$. In the case of the 5-phase machine $(n=5)$, the first machine (MM, $g=1)$ is associated with the odd harmonics $5 h \pm 1$, and the Secondary Machine (SM, $g=2$ ) with the odd harmonics $5 h \pm 2$.

\section{1) Projection onto eigenspace $G_{2 g}$}

Expression (19) shows that the torque $T_{2 g}$ is the dot product of projections of two vectors. The first one is only depending on the design of the machine, the second one is imposed by the power supply. To characterize the fictitious machine, $d \overrightarrow{\phi_{s r}} / d \theta=\overrightarrow{q(\theta)}$ is analyzed.

As $\overrightarrow{q(\theta)}$ is a $2 \pi p$ periodic function, each one of its $n$ components, $q_{k}$, can be decomposed into a Fourier series. Properties of symmetry, due to the regular manufacturing assumption of the rotating machine, involve, as usual, the cancellation of cosine terms and of even sine terms.

$$
\begin{gathered}
q_{k}(\alpha)=\sum_{e=1, e \neq 2 h}^{+\infty} w_{e} \sin \left[\operatorname{ep}\left(\alpha-(k-1) \frac{2 \pi}{n p}\right)\right] \\
w_{e}=\frac{p}{\pi} \int_{-\frac{\pi}{p}}^{\frac{\pi}{p}} q_{l}(\alpha) \sin (e p \alpha) d \alpha
\end{gathered}
$$

To get components of $\overrightarrow{q(\alpha)}$ in the different eigenspaces, the equation must be inserted in the following vectorial expression of $\overrightarrow{q(\alpha)}$ in the natural basis:

$$
\overrightarrow{q(\alpha)}=\sum_{k=1}^{k=n} q_{k}(\alpha) \overrightarrow{x_{k}^{\sigma}}
$$

By combination of (21) and (23), $\overrightarrow{q(\alpha)}$ becomes:

$$
\overrightarrow{q(\alpha)}=\sum_{e=1, e \neq 2 h}^{+\infty} w_{e} \overrightarrow{g_{e}(\alpha)}
$$

with

$$
\overrightarrow{g_{e}(\alpha)}=\sum_{k=1}^{k=n} \sin \left(e p\left(\alpha-\frac{2 \pi}{n p}(k-1)\right)\right) \overrightarrow{x_{k}^{\sigma}}
$$

$\overrightarrow{q(\alpha)}$ has been expressed as a sum of $\mathrm{n}$ vectors $\overrightarrow{g_{e}(\alpha)}$. It is sufficient to study the projections of $\overrightarrow{g_{e}(\alpha)}$.

\section{2) Family of harmonics}

Let us calculate the projection of the vector $\overrightarrow{g_{e}(\alpha)}$ onto the subspace $G_{2 g}$. The dot product of $\overrightarrow{g_{e}(\alpha)}$ by $\overrightarrow{x_{g}^{d}}$ and $\overrightarrow{x_{g+1}^{d}}$ (two vectors of a base of $G_{2 g}$ ) is evaluated:

$\overrightarrow{g_{e}(\alpha)} \cdot \overrightarrow{x_{g}^{d}}=\sqrt{\frac{2}{n}} \sum_{k=1}^{k=n} \sin \left(\right.$ ep $\left.\alpha-\frac{2 \pi}{n} e(k-1)\right) \cos \left(\frac{2 \pi}{n} g(k-1)\right)=$

$\sqrt{\frac{1}{2 n}} \sum_{k=1}^{k=n} \sin \left(\operatorname{ep} \alpha-\frac{2 \pi}{n} e(k-1)+\frac{2 \pi}{n} g(k-1)\right)+$

$\sqrt{\frac{1}{2 n}} \sum_{k=1}^{k=n} \sin \left(\right.$ ep $\left.\alpha-\frac{2 \pi}{n} e(k-1)-\frac{2 \pi}{n} g(k-1)\right)=$

$\sqrt{\frac{1}{2 n}} \sum_{k=1}^{k=n} \sin \left(\operatorname{ep} \alpha-\frac{2 \pi}{n}(k-1)(e-g)\right)+$

$\sqrt{\frac{1}{2 n}} \sum_{k=1}^{k=n} \sin \left(\operatorname{ep} \alpha-\frac{2 \pi}{n}(k-1)(e+g)\right)=$

$\sqrt{\frac{1}{2 n}} \operatorname{Im}\left(\sum_{k=1}^{k=n} e^{j e p \alpha}\left[e^{\left[-j \frac{2 \pi}{n}(e-g)\right](k-1)}+e^{\left[-j \frac{2 \pi}{n}(e+g)\right](k-1)}\right]\right.$

With the same approach:

$$
\begin{aligned}
& \overrightarrow{g_{e}(\alpha)} \cdot \overrightarrow{x_{g+1}^{d}}=\sqrt{\frac{2}{n}} \sum_{k=1}^{k=n} \sin \left(\text { ep } \alpha-\frac{2 \pi}{n} e(k-1)\right) \sin \left(\frac{2 \pi}{n} g(k-1)\right)= \\
& \sqrt{\frac{1}{2 n}} \sum_{k=1}^{k=n} \cos \left(e p \alpha-\frac{2 \pi}{n} e(k-1)+\frac{2 \pi}{n} g(k-1)\right)- \\
& \sqrt{\frac{1}{2 n}} \sum_{k=1}^{k=n} \cos \left(\text { ep } \alpha-\frac{2 \pi}{n} e(k-1)-\frac{2 \pi}{n} g(k-1)\right)= \\
& \sqrt{\frac{1}{2 n}} \sum_{k=1}^{k=n} \cos \left(\text { ep } \alpha-\frac{2 \pi}{n}(k-1)(e-g)\right)- \\
& \sqrt{\frac{1}{2 n}} \sum_{k=1}^{k=n} \cos \left(\text { ep } \alpha-\frac{2 \pi}{n}(k-1)(e+g)\right)= \\
& \sqrt{\frac{1}{2 n}} \operatorname{Re}\left(\sum _ { k = 1 } ^ { k = n } e ^ { j e p \alpha } \left[e^{\left[-j \frac{2 \pi}{n}(e-g)\right](k-1)}-e^{\left.\left[-j \frac{2 \pi}{n}(e+g)\right](k-1)\right]}\right.\right.
\end{aligned}
$$

As $1+x+x^{2}+\ldots+x^{n-1}=\frac{1-x^{n}}{1-x}$ unless $x=1$, we get the following results:

\begin{tabular}{|l|l|l|}
\hline For $h$ positive integer & $\overrightarrow{g_{e}(\alpha)} \cdot \overrightarrow{x_{g}^{d}}$ & $\overrightarrow{g_{e}(\alpha) \cdot \overrightarrow{x_{g+1}^{d}}}$ \\
\hline$e=n h+g$ and odd number & $\sqrt{\frac{n}{2}} \sin ($ ep $\alpha)$ & $\sqrt{\frac{n}{2}} \cos ($ ep $\alpha)$ \\
\hline$e=n h-g$ and odd number & $\sqrt{\frac{n}{2}} \sin ($ ep $\alpha)$ & $-\sqrt{\frac{n}{2}} \cos ($ ep $\alpha)$ \\
\hline$e+g \neq n h$ and $e-g \neq n h$ & 0 & 0 \\
\hline
\end{tabular}


It appears that the family of odd harmonics verifying $e=n h \pm g$ is associated with the eigenspace $G_{2 g}$. According to the considered eigenspace associated with the fictitious studied machine, the null terms of the Fourier series are not the same. There is a distribution of the different space harmonics between the eigenspaces.

\section{3) References and examples}

This kind of harmonic characterization has already been observed in [14] by E. Klingshirn, studying multi-phase induction motors supplied by PAM VSI: in steady states, an harmonic analysis of the periodic voltages shows that there are families of harmonics which are each one associated with a particular impedance of the motor.

For transient states, [10] has also in the particular case of a 6-phase induction machine exhibited, using a matrix approach, harmonic families associated with particular eigenspaces.

Other harmonic studies [15]-[18] have been also realized for $n$-phase machines but have not exhibited neither the fictitious machines nor the independence of the different families of harmonics.

In the following tables, examples of Multi-machine characterization are given.

TABLE I. HARMONIC CHARACTERIZATION FOR WYE-COUPLED 3-PHASE MACHINE

\begin{tabular}{|c|c|c|}
\hline $\begin{array}{c}\text { Fictitious } \\
\text { machine }\end{array}$ & Eigenspace & $\begin{array}{c}\text { Families of odd } \\
\text { harmonics }\end{array}$ \\
\hline $\begin{array}{c}\text { First 2-phase } \\
\text { machine }\end{array}$ & $\mathrm{G}_{2}$ & $1,5,7, \ldots, 3 h \pm 1$ \\
\hline
\end{tabular}

TABLE II. HARMONIC CHARACTERIZATION FOR WYE-COUPLED 5-PHASE MACHINE

\begin{tabular}{|c|c|c|}
\hline Fictitious machine & Eigenspace & Families of odd harmonics \\
\hline First 2-phase machine & $\mathrm{G}_{2}$ & $1,9,11, \ldots, 5 h \pm 1$ \\
\hline Second 2-phase machine & $\mathrm{G}_{4}$ & $3,7,13 \ldots, 5 h \pm 2$ \\
\hline
\end{tabular}

TABLE III. HARMONIC CHARACTERIZATION FOR WYE-COUPLED 7-PHASE MACHINE

\begin{tabular}{|c|c|c|}
\hline Fictitious machine & Eigenspace & Families of odd harmonics \\
\hline First 2-phase machine & $\mathrm{G}_{2}$ & $1,13,15, \ldots, 7 h \pm 1$ \\
\hline Second 2-phase machine & $\mathrm{G}_{4}$ & $5,9,19 \ldots, 7 h \pm 2$ \\
\hline Third 2-phase machine & $\mathrm{G}_{6}$ & $3,11,17 \ldots, 7 h \pm 3$ \\
\hline
\end{tabular}

TABLE IV. HARMONIC CHARACTERIZATION FOR WYE-COUPLED 9-PHASE MACHINE

\begin{tabular}{|c|c|}
\hline Fictitious machine & Families of odd harmonics \\
\hline First 2-phase machine & $1,17,19, \ldots, 9 h \pm 1$ \\
\hline Second 2-phase machine & $7,11,25 \ldots, 9 h \pm 2$ \\
\hline Third 2-phase machine & $3,15,21 \ldots, 9 h \pm 3$ \\
\hline Fourth 2-phase machine & $5,13,23 \ldots, 9 h \pm 4$ \\
\hline
\end{tabular}

\section{RIGHT HARMONIC SPECTRUM OF BACK-EMF FOR EFFICIENT CONTROL}

The Multi-machine modeling of $n$-phase machine is used to find right characteristics of the machine for efficient vector control.
If the back EMFs of a 3-phase machine have a sinusoidal waveform then current controls in synchronous frame permit to achieve high efficient brushless DC machines particularly at low speeds [3].

It has been shown that the control of a $n$-phase machine is equivalent to the control of $(n-1) / 2$ 2-phase fictitious machines. To be able to use algorithms developed for sine wave 3-phase machines, it is enough to have only one harmonic per fictitious machine. Each fictitious machine is then a sine wave one. For each fictitious machine it is then possible to work in a frame where the back EMF has a constant value. To get constant torque the reference current $i_{\text {ref }}$ is then constant: a simple Proportional Integral controller is convenient for each fictitious machine.

Consequently, the equivalent case of a sine-wave 3-phase machine for a $n$-phase one is that the spectrum of back electromotive force must contain only odd $2 k+1$ harmonics which verify the following inequality, $1 \leq 2 k+1<n$.

For a 5-phase machine for example the back-EMF has only to contain the first and third harmonics. The corresponding synopsis of control is presented in Fig.7.

After a choice of repartition of the torque reference $T_{\text {em-ref }}$ between the two fictitious machines, two independent controls using the same algorithm as for vector control of 3-phase machines are used. The unique difference is that the angle of the matrix rotation relative to the secondary machine is $3 \theta$ instead of $\theta$. Such a control has been implemented for an experimental 5-phase machine whose characteristics of back EMF (Fig.6) are given in TABLE V.

One can remark that the main machine is almost a machine with a sinusoidal back-EMF since the $9^{\text {th }}$ represents only $1,7 \%$ of the first harmonic. For the secondary machine, the $7^{\text {th }}$ harmonic of back-EMF, which is only $5,1 \%$ of the fundamental, represents $18 \%$ of the $3^{\text {rd }}$ harmonic. Consequently, the back-EMF of SM can not be considered as sinusoidal because it is composed of $3^{\text {rd }}$ and $7^{\text {th }}$ harmonics.

TABLE V. HARMONIC DECOMPOSITION OF BACK-ELECTROMOTIVE OF ONE PHASE

\begin{tabular}{|c|c|c|c|c|c|}
\hline Order of harmonic & 1 & 3 & 5 & 7 & 9 \\
\hline Relative RMS amplitude & $100 \%$ & $28,5 \%$ & $12,4 \%$ & $5,1 \%$ & $1,7 \%$ \\
\hline
\end{tabular}

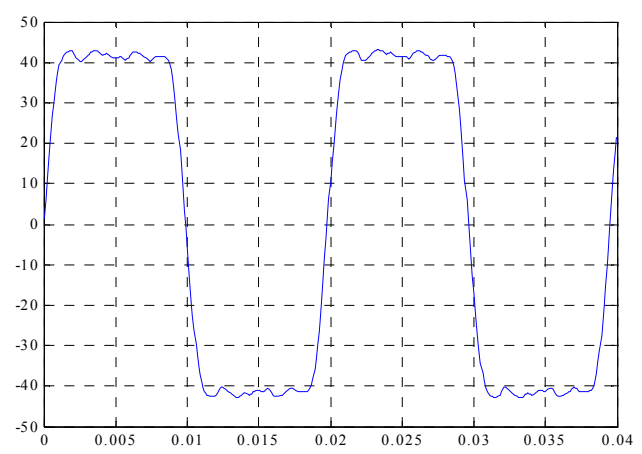

Figure 6. Back electromotive force of 5-phase machine. 


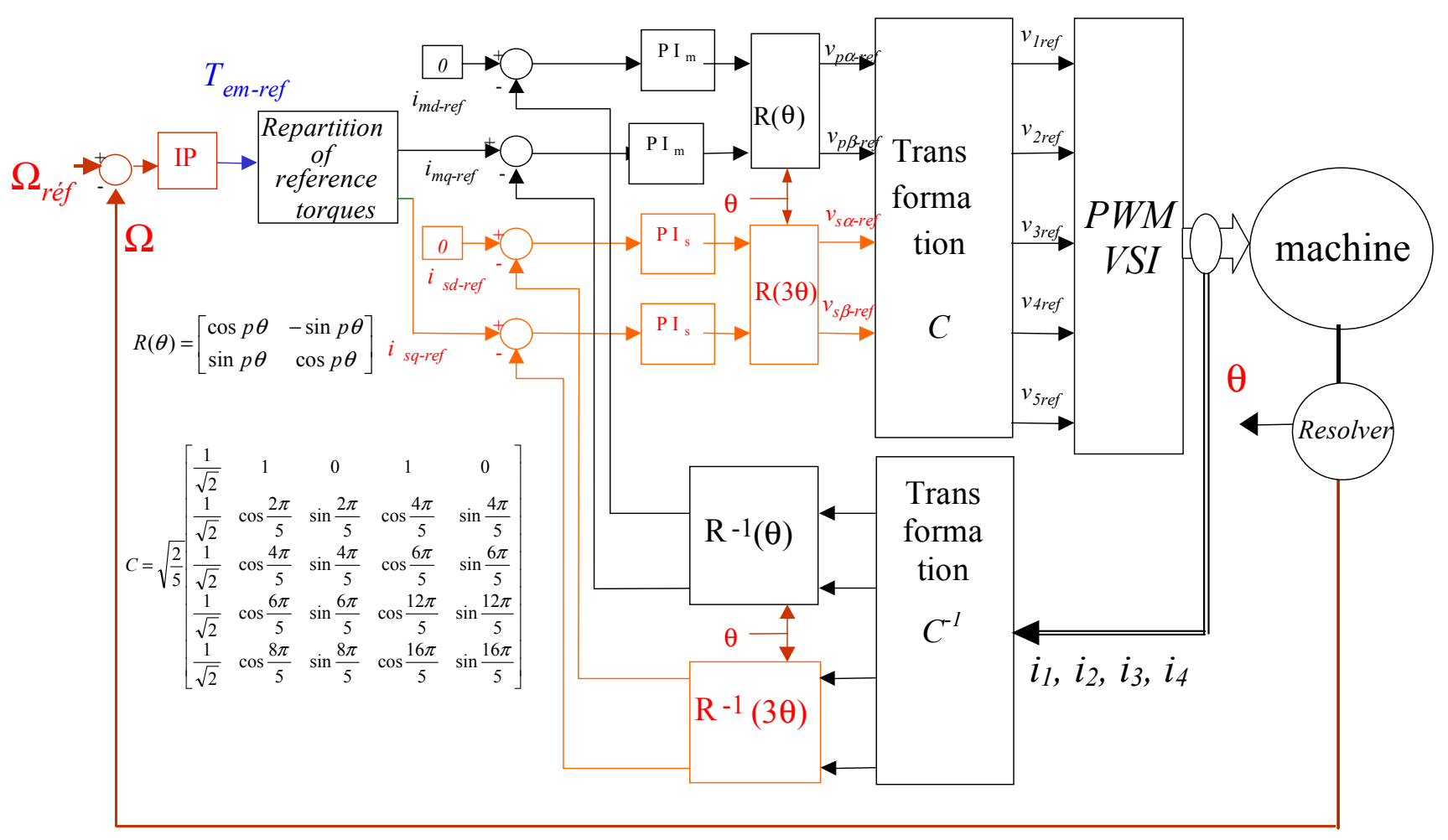

Figure 7. Synopsis of control.

To exhibit the influence of the $7^{\text {th }}$ harmonic on the performance of the drive, it has been chosen to use only the Main Machine to produce the torque. In the ideal case of a machine with only the $1^{\text {st }}$ and $3^{\text {rd }}$ harmonics in the back emf it should appear only the first harmonic in the spectrum of the current. In Fig. 8 and Fig. 10 effects of $7^{\text {th }}$ harmonic of EMF are visible on the current in the phase $n^{\circ} 1$. Fig. 12 shows currents in each frame of the fictitious machines: it is effectively in the Secondary Machine that the $7^{\text {th }}$ harmonic appears. It is consequently necessary to compensate the negative effect of the $7^{\text {th }}$ harmonic in the control of Secondary Machine. In Fig.9 and Fig.11 effects of compensation of $7^{\text {th }}$ harmonic of EMF are shown.

In a second strategy, the two fictitious machines have been used to produce torque with a compensation of the $7^{\text {th }}$ harmonic. Fig.14., Fig. 15, Fig. 16 and Fig.17 gives results of the vector control. More explanations about this control are given in [19].

\section{CONCLUSION}

In this paper, a Multi-machine modeling of $n$-phase machines has been presented. This approach exhibits particularities of $n$ phase machine beyond 3-phase ones: it is possible to get the total torque using different fictitious machines. The choice of the repartition of the total torque between the different machines depends on the characteristic of the fictitious machines whose harmonic characterization has been given. To use algorithms already developed for vector control of 3-phase machine, it is sufficient that each fictitious machine has sinusoidal waveform EMF.

\section{ACKNOWLEDGMENT}

This work is part of the project 'Futurelec2' within the 'National Center of Technological Research' (CNRT) of Lille. The support of the CNRT is kindly acknowledged.

\section{REFERENCES}

[1] T.M. Jahns, “Improved reliability in solid state ac drives by means of multiple independent phase-drive units", IEEE Transactions on Industry Applications, vol. IA-16, May-June 1980, pp. 321-331.

[2] H.A. Toliyat, "Analysis and Simulation of Five-Phase Variable-Speed Induction Motor Drives Under Asymmetrical Connections", IEEE Transactions on Power Electronics, vol. 13 no 4, July 1998, pp. 748756.

[3] D.W. Novotny, T.A. Lipo, Vector Control and dynamics of AC drives, New York, Oxford University Press Inc, 2000.

[4] R. Shi R., H. A. Toliyat, A. El-Antably, "Field Oriented Control of Fivephase Synchronous Reluctance Motor Drive with Flexible 3rd Harmonic Current Injection for High Specific Torque “, IEEE-IAS annual meeting 2001, September/October 2001, Chicago (USA), CD-ROM.

[5] J. Figueroa, J. Cros, P. Viarouge, "Current Control Strategies for Seven Phase Brushless DC Motors", International Congress on Electrical Machines (ICEM'02), August 2002, Brugges (Belgium), CD-ROM.

[6] G. Simões, P. Vieira, "A High-Torque Low-Speed Multiphase Brushless Machine-A Perspective Application”, IEEE Transactions on Industrial Electronics, vol. 49, no. 5, October 2002, pp. 1154-1164.

[7] E. Semail, A. Bouscayrol, J.P. Hautier, "Vectorial formalism for analysis and design of polyphase synchronous machines", EPJ AP (European Physical Journal-Applied Physics), vol. 22 no 3, June 2003, pp. 207-220. 
[8] X. Kestelyn, "Vectorial Multi-machine Modeling for the control of Multi-phase drives ", Ph.D. thesis, University of Sciences and Technologies of Lille, December 2003 (text in French).

[9] X. Kestelyn, E. Semail, JP. Hautier, "Vectorial Multi-machine modeling for a five-phase machine", International Congress on Electrical Machines (ICEM'02), August 2002, Brugges (Belgium), CD-ROM.

[10] Y. Zhao, T. A. Lipo, “ Space Vector PWM Control of Dual ThreePhase Induction Machine Using Space Vector Decomposition ", IEEE Transactions on Industry Applications, vol. 31 no 5, September/October 1995, pp. 1100-1109.

[11] F. Scuiller, E. Semail, J.F. Charpentier and S. Clénet, "Comparison of conventionnal and unconventionnal 5-phase PM motor structures for naval application system", WSEAS 2004, Electroscience and Technology for Naval Engineering and All-electric ship, Greece, athens, july 12-15, 2004, CD-ROM.

[12] A. Bouscayrol, B. Davat, B. de Fornel, B. François, J. P. Hautier, F. Meibody-Tabar, E. Monmasson, M. Pietrzak-David, H. Razik, E. Semail, M. F. Benkhoris, "Control Structures for Multi-machine Multiconverter Systems with upstream coupling", Mathematics and Computers in Simulation, vol. 63, no3-5, November 2003, pp. 261-270.

[13] A. Bouscayrol , B. Davat, B. De Fornel, B.François, J. P. Hautier, F. Meibody-Tabar, M. Pietrzak-David, "Multi-machine multi-converter

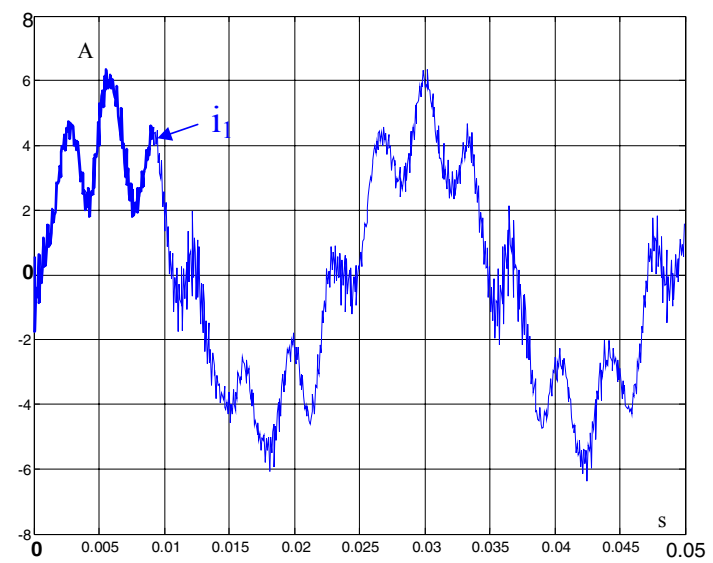

Figure 8. Experimental $i_{1}$ current in phase $n^{\circ} 1$ at $1000 \mathrm{rpm}$ without compensation of $7^{\text {th }}$ harmonic of back-EMF.

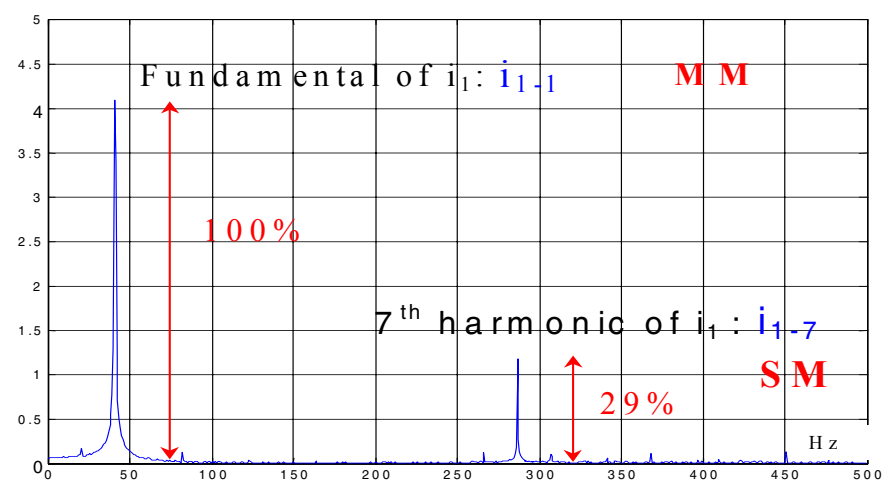

Figure 10. Spectrum of experimental current $i_{1}$ at $1000 \mathrm{rpm}$ without compensation of $7^{\text {th }}$ harmonic of back-EMF. systems: applications to electromechanical drives", EPJ Applied Physics, Vol. 10, no. 2, May 2000, pp131-147.

[14] E.A. Klingshirn, " High phase order induction motors _ Part I and II", IEEE Trans. Power Apparatus Systems, vol PAS -102, 1983, pp. 47-59.

[15] C. Hodge, S.Williamson, S. Smith, « Direct Drive Marine Propulsion Motors ", International Congress on Electrical Machines (ICEM'02), August 2002, Brugges (Belgium), CD-ROM.

[16] H.A. Toliyat, T.A. Lipo, J. C. White, “Analysis of a Concentrated Winding Induction Machine for Adjustable Speed Drive Application Part 1 (Motor Analysis)", IEEE Transactions on Energy Conversion, Vol. 6, no.4, 1991, pp. 679-683.

[17] H.A. Toliyat, T.A. Lipo, J. C. White, « Analysis of a Concentrated Winding Induction Machine for Adjustable Speed Drive Application Part 2 (Motor design and Performance)», IEEE Transactions on Energy Conversion, Vol 6 no. 4, 1991, pp. 684-692.

[18] L. Parsa, H. A. Toliyat, «Multi-Phase Permanent Magnet Motor Drives", IEEE-IAS annual meeting 2003, Salt Lake City (Utah), October 12-16, CD-ROM.

[19] E. Semail, X. Kestelyn, A. Bouscayrol, "Sensitivity of a 5-phase Brushless DC machine to the 7th harmonic of the back-electromotive force", PESC 2004, IEEE Power Electronics Specialists Conference, Aachen, Germany in June 20 - 25, 2004, CD-ROM.

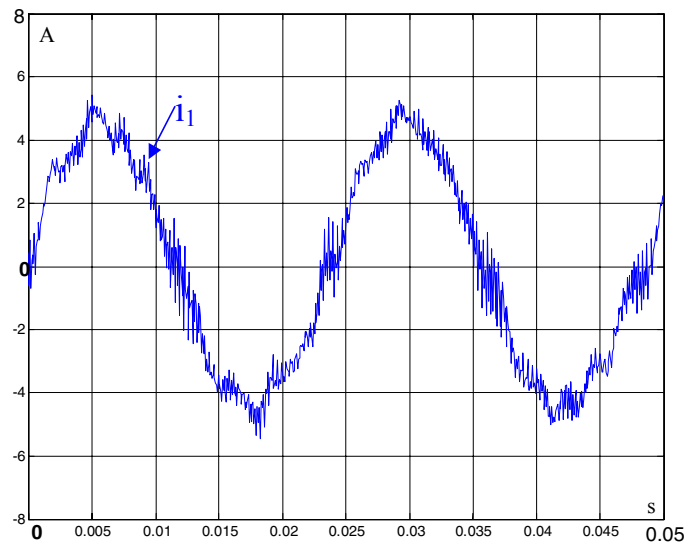

Figure 9. Experimental $i_{1}$ current in phase $n^{\circ} 1$ at $1000 \mathrm{rpm}$ with compensation of $7^{\text {th }}$ harmonic of back-EMF.

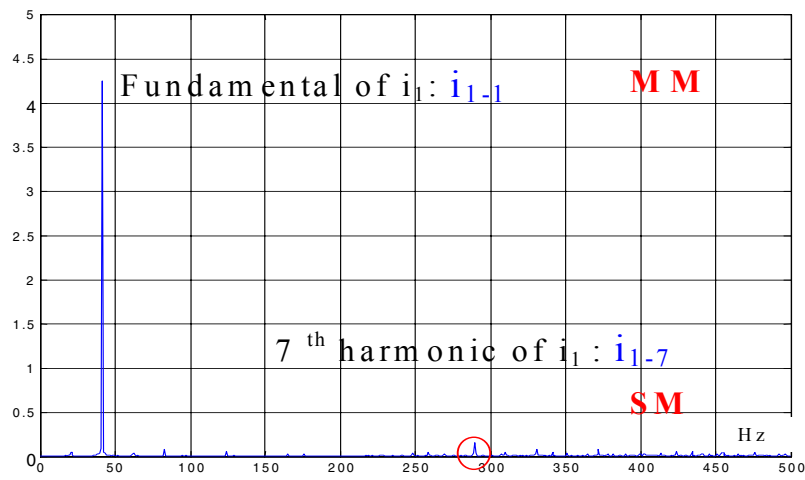

Figure 11. Spectrum of experimental current $i_{1}$ at $1000 \mathrm{rpm}$ with compensation of $7^{\text {th }}$ harmonic of back-EMF. 

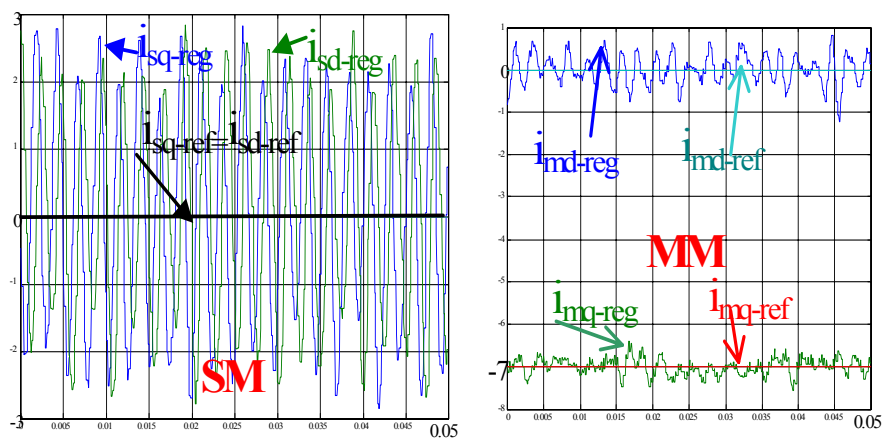

Figure 12. Currents in the two fictitious 2-phase machines 'MM' and 'SM' without compensation of $7^{\text {th }}$ harmonic of back-EMF.

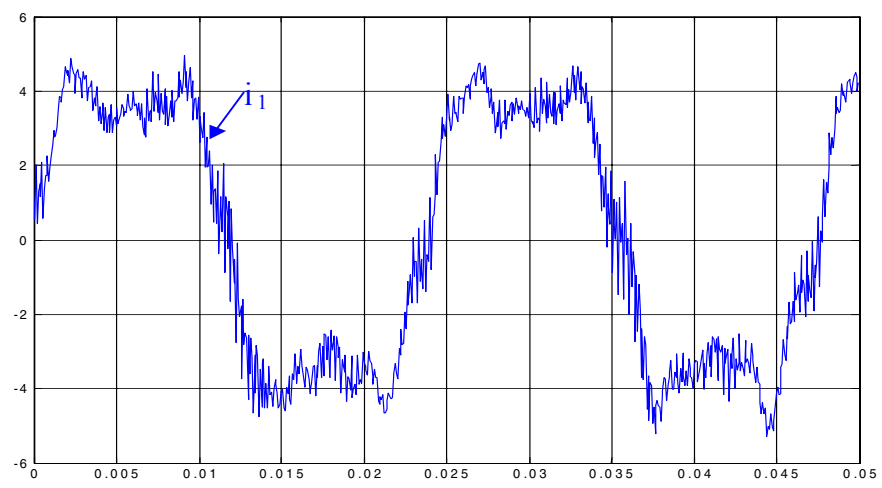

Figure 14. Experimental $i_{1}$ current in phase $n^{\circ} 1$ at $1000 \mathrm{rpm}$ with compensation of $7^{\text {th }}$ harmonic of back-EMF and the repartition between MM and SM $\mathrm{i}_{\mathrm{sq}-\text { ref }}=(29 \%) \mathrm{i}_{\mathrm{mq}-\text {-ref. }}$.

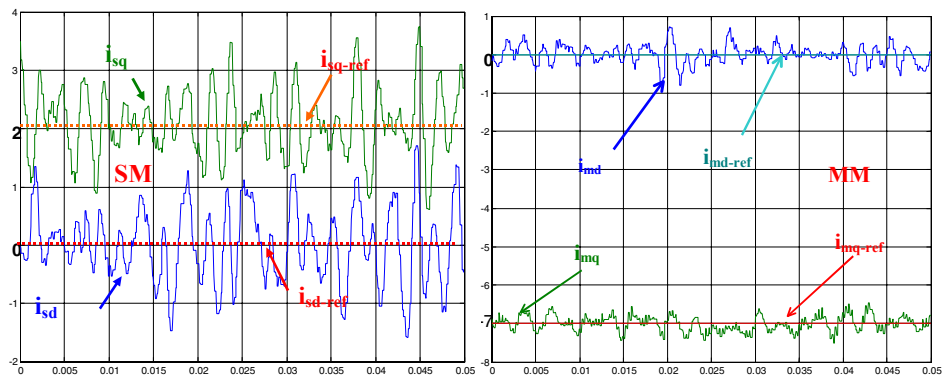

Figure 16. Currents in the two fictitious 2-phase machines 'MM' and 'SM' with compensation of $7^{\text {th }}$ harmonic of back-EMF.
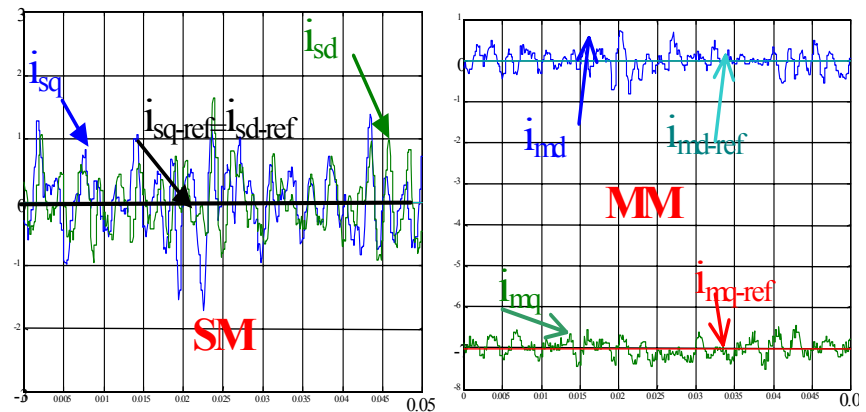

Figure 13. Currents in the two fictitious 2-phase machines 'MM' and 'SM' with compensation of $7^{\text {th }}$ harmonic of back-EMF.

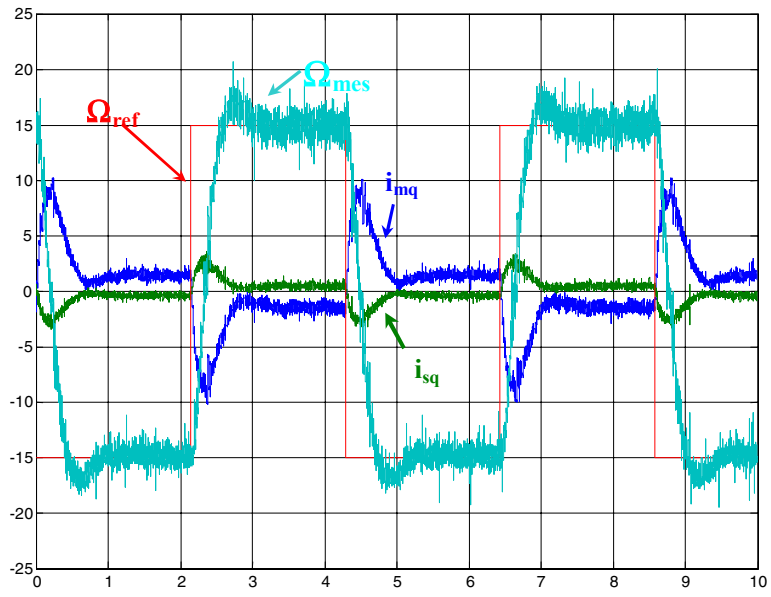

Figure 15. Experimental active currents in $\mathrm{MM}$ and $\mathrm{SM}$ with compensation of $7^{\text {th }}$ harmonic of back-EMF and $\mathrm{T}_{\text {es-ref }}=(29 \%) \mathrm{T}_{\text {ms-ref. }}$

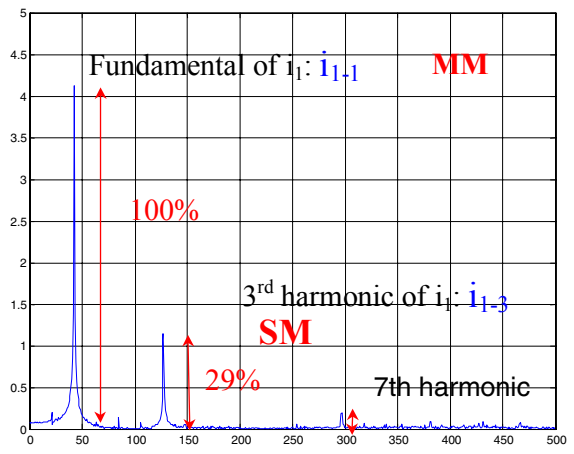

Figure 17. Spectrum of Figure 14 experimental current $i_{1}$. 